\title{
Impacto da limpeza e higiene hospitalar no espaço de gestão do enfermeiro: revisão
}

\section{de literatura}

\author{
Impact of cleaning and hospital hygiene on the nurses' management space: literature review \\ Impacto de la limpieza y la higiene hospitalaria en el espacio de gestión de enfermeras: revisión de
}

\section{la literatura}

Recebido: 07/03/2021 | Revisado: 12/03/2021 | Aceito: 15/03/2021 | Publicado: 22/03/2021

Karen Silva de Castro

ORCID: https://orcid.org/0000-0001-8463-0322 Universidade do Estado do Pará, Brasil E-mail: silvakaren2021@gmail.com

Michele Pinheiro Ferreira

ORCID: https://orcid.org/0000-0001-5316-9908 Universidade do Estado do Pará, Brasil

E-mail: michelepinheiroferreira@ gmail.com

Lauany Silva de Medeiros

ORCID: https://orcid.org/0000-0002-5683-6347 Universidade do Estado do Pará, Brasil E-mail: lauanymedeiiros@gmail.com

Nayara Fernanda Alves Moreira

ORCID: https://orcid.org/0000-0003-1094-7399 Universidade do Estado do Pará, Brasil E-mail: nfernandamoreira@gmail.com Daniele Lima dos Anjos Reis

ORCID: https://orcid.org/0000-0002-8447-6828 Universidade do Estado do Pará, Brasil

E-mail: anjo.daniele@hotmail.com

Jose Ronaldo Teixeira de Sousa Junior

ORCID: https://orcid.org/0000-0002-8730-9304

Centro Universitário do Estado do Pará, Brasil

E-mail: ronaldosousajr@gmail.com

Milena Coelho Fernandes Caldato

ORCID: https://orcid.org/0000-0002-7077-8470 Universidade Federal do Pará, Brasil E-mail milenacaldato@hotmail.com

Ismaelino Mauro Nunes Magno

ORCID: https://orcid.org/0000-0003-3323-1465 Universidade Federal do Pará, Brasil E-mail: mauromagno@cesupa.br Genislaine Ferreira Pereira

ORCID: https://orcid.org/0000-0002-4565-0379 Prefeitura Municipal de Tucuruí, Brasil E-mail: genislaine_fp@hotmail.com

Renata Campos de Sousa Borges

ORCID: https://orcid.org/0000-0002-7510-5582 Universidade do Estado do Pará, Brasil E-mail: renatasousa88@hotmail.com

\section{Resumo}

Realizar uma revisão de literatura para a análise dos desafios enfrentados pelos profissionais da enfermagem para a efetivação da higienização hospitalar, abordando uma percepção multifacetada da trajetória relacionada à problemática. Trata-se de uma pesquisa exploratória do tipo revisão de literatura, sendo um método imprescindível na elaboração de um trabalho científico. Foi dividido em 6 etapas, com a criação da temática e questão norteadora, definição dos critérios de inclusão e exclusão, identificação dos estudos nas bases científicas, avaliação dos estudos selecionados e análise crítica, análise e categorização dos estudos e avaliação e interpretação dos resultados. $\mathrm{O}$ total de estudos incluídos foi de 26 artigos, estimando o maior percentual contabilizado de produções sobre o tema com $30,77 \%$ no ano de 2016, acompanhado de $26,92 \%$ no ano de 2017 , seguido de $15,38 \%, 11,54 \%$ e $19,23 \%$ encontrados simultaneamente nos anos de 2018, 2019 e 2020. Os artigos analisados convergem no sentido de que a equipe de enfermagem é essencial para o sucesso da manutenção da higiene nos setores hospitalares, sendo tal ato fundamental para a manutenção ou/e diminuição de danos à saúde do paciente. Percebemos, assim, a importância do conhecimento 
histórico para compreensão do cenário atual do país, pois, a partir das ideologias ambientais e sanitárias defendidas por ativistas do século XIX.

Palavras-chave: Higiene; Prevenção; Enfermagem; Saúde pública.

\begin{abstract}
Conduct a literature review to analyze the challenges faced by nursing professionals in order to carry out hospital hygiene, addressing a multifaceted perception of the trajectory related to the problem. It is an exploratory research of the literature review type, being an essential method in the elaboration of a scientific work. It was divided into 6 stages, with the creation of the theme and guiding question, definition of inclusion and exclusion criteria, identification of studies on scientific bases, evaluation of selected studies and critical analysis, analysis and categorization of studies and evaluation and interpretation of results. The total number of studies included was 26 articles, estimating the highest percentage of productions on the subject accounted for $30.77 \%$ in 2016, followed by $26.92 \%$ in 2017 , followed by $15.38 \%, 11,54 \%$ and $19.23 \%$ found simultaneously in the years 2018, 2019 and 2020 . The analyzed articles converge in the sense that the nursing team is essential for the success of the maintenance of hygiene in the hospital sectors, being such a fundamental act for the maintenance or / and decreased damage to the patient's health. We realize, therefore, the importance of historical knowledge to understand the current scenario of the country, since, from the environmental and health ideologies defended by activists of the 19th century.
\end{abstract}

Keywords: Hygiene; Prevention; Nursing; Public health.

\title{
Resumen
}

Realizar una revisión de la literatura para analizar los desafíos que enfrentan los profesionales de enfermería para llevar a cabo la higiene hospitalaria, abordando una percepción multifacética de la trayectoria relacionada con el problema. Se trata de una investigación exploratoria del tipo revisión de la literatura, siendo un método imprescindible en la elaboración de un trabajo científico. Se dividió en 6 etapas, con la creación del tema y pregunta orientadora, definición de criterios de inclusión y exclusión, identificación de estudios con bases científicas, evaluación de estudios seleccionados y análisis crítico, análisis y categorización de estudios y evaluación e interpretación de resultados. . El total de estudios incluidos fue de 26 artículos, estimándose que el mayor porcentaje de producciones sobre el tema representó el $30,77 \%$ en 2016 , seguido del $26,92 \%$ en 2017 , seguido del $15,38 \%, 11,54 \%$ y $19,23 \%$ encontrados simultáneamente en los años. 2018, 2019 y 2020. Los artículos analizados convergen en el sentido de que el equipo de enfermería es fundamental para el éxito del mantenimiento de la higiene en los sectores hospitalarios, siendo un acto tan fundamental para el mantenimiento y / y disminución del daño a la salud del paciente. Nos damos cuenta, por tanto, de la importancia del conocimiento histórico para comprender el escenario actual del país, desde las ideologías ambientales y de salud defendidas por activistas del siglo XIX.

Palabras clave: Higiene; Prevención; Enfermería; Salud pública.

\section{Introdução}

Desde os primórdios da humanidade, é evidente que a história influencia na realidade social. A partir disso, a Enfermagem Contemporânea foi instigada por marcos histórico como, a Guerra da Criméia na Inglaterra onde, houve a convocação de Florence Nightingale, pioneira da enfermagem moderna para auxiliar no campo de batalha em um hospital de caridade, o que a fez observar e refletir o ambiente em que os doentes estavam expostos e de que forma poderia contribuir para o auto índice de mortes, visto que, eram locais insalubres com baixa infraestrutura, iluminação e escassez de materiais (Bezerra, 2018).

Nesse sentido, a aplicação de novos parâmetros de cuidado, baseando-se na limpeza do local dos enfermos e oferecendo iluminação adequada, oportunizou a diminuição abrupta no número de mortes, comprovando a teoria de Florence. Posteriormente, foi estabelecida a Teoria Ambientalista, na qual apresenta como foco principal o meio ambiente, onde todas as condições e influências externas afetam a vida e o desenvolvimento do organismo, e são capazes de prevenir, suprimir, ou contribuir para a doença e a morte (Borson, 2018).

Ademais, por meio de suas teorias aplicadas e comprovadas, Florence estabeleceu um padrão científico assistencial ao enfermeiro, que mais adiante se denominou como o Processo de Enfermagem (PE) destacando a execução de procedimentos de assistência básica decorridos em seis fases: histórico, diagnóstico, plano assistencial, plano de cuidado, evolução e prognóstico de enfermagem (Potter \& Perry, 2009). 
Em consonância, no Brasil a enfermagem foi introduzida por Ana Justina Ferreira, no ano de 1870, após retornar da Guerra do Paraguai, na qual atuou no hospital militar de Assunção, deparando-se com um cenário de soldados doentes em ambientes sem saneamento e propícios a disseminação de infecções. Tal cenário, motivou a utilização de meios para melhorar a aparência física dos pacientes e higiene das unidades de batalhas. Desse modo, essa estratégia de atuação profissional da enfermagem configurou-se como uma das principais áreas de assistência clínica da saúde básica (Grisard \& Vieira, 2009).

A partir do exposto, compreende-se que a desinfecção e limpeza de áreas são componentes que tendem a produzir um ambiente confortável e, consequentemente, segurança, conforto e sensação de bem estar aos pacientes, família e profissionais nos serviços de saúde, pois suas atuações estão diretamente relacionadas ao controle de infecções referente à assistência de saúde. Garantindo um local com superfícies limpas, com número de microrganismo abaixo do esperado, e congruente para a efetivação das atividades oferecidas nesses estabelecimentos (Campos \& Jesus, 2015).

Nesse sentido, ao longo dos últimos anos, a higienização hospitalar é considerada atividade fundamental tanto para o bem-estar físico e psicológico dos clientes e profissionais, como favorece de maneira essencial o controle e prevenção de infecções no âmbito hospitalar, determinando que os hospitais e clinicas ofereçam capacitação e aperfeiçoamento aos profissionais no que tange a higienização desses estabelecimentos de saúde. Todavia, é evidente que as irregularidades na efetivação desse processo produzem consequências como, disseminação e transferência de microrganismos do ambiente para o paciente, colocando em risco a sua segurança e a dos profissionais da área de saúde (Martins, Maia, \& Dantas, 2016).

Logo, este trabalho tem como objetivo realizar uma revisão de literatura para a análise dos desafios enfrentados pelos profissionais da enfermagem para a efetivação da higienização hospitalar, abordando uma percepção multifacetada da trajetória relacionada à problemática.

\section{Metodologia}

Trata-se de uma pesquisa qualitativa (Pereira et al, 2018), de caráter exploratório do tipo revisão de literatura, sendo um método é imprescindível para a elaboração de um trabalho científico. O pesquisador deve acreditar na sua importância para a qualidade do projeto e da pesquisa e que tudo é aproveitável para os relatórios posteriores. Na elaboração do trabalho científico é preciso ter uma ideia clara do problema a ser resolvido e, para que ocorra esta clareza, a revisão de literatura é fundamental. Perry e Potter (2019) afirmam que:

Os métodos qualitativos são aqueles nos quais é importante a interpretação por parte do pesquisador com suas opiniões sobre o fenômeno em estudo. Neles a coleta de dados muitas vezes ocorre por meio de entrevistas com questões abertas (Pereira, 2018, p. 67-68).

A seleção criteriosa de uma revisão de literatura pertinente ao problema significa familiarizar-se com textos e por eles, reconhecer os autores e o que eles estudaram anteriormente sobre o problema a ser estudado. O estímulo ao pensamento e a definição de um problema de investigação de caráter científico têm como ponto de partida e de chegada a revisão de literatura sobre o tema (Perry \& Potter, 2019, p. 672-680).

Assim, durante o desenvolvimento dessa revisão, foram percorridas etapas, como: 1) criação da temática e questão norteadora; 2) definição dos critérios de inclusão e exclusão; 3) identificação dos estudos nas bases científicas; 4) avaliação dos estudos selecionados e análise crítica; 5) análise e categorização dos estudos e 6) avaliação e interpretação dos resultados (publicação da revisão).

Desse modo, as questões norteadoras foram: "Qual o papel da enfermagem o contexto da higiene hospitalar" e "Qual os desafios desta problemática?". A realização das buscas ocorreu em agosto e setembro de 2020, usando as bases de dados Literatura Latino-americana e do Caribe em Ciências da Saúde (LILACS), Scientific Electronic Library Online (SciELO), 
PubMed e Google scholar com recorte temporal de 2016 a 2020, sendo que houve uma triagem criteriosa quanto ao tipo (teses e dissertações) e periódico da publicação representado no Esquema 1.

Os descritores associados foram: "Equipe de enfermagem", "Setor hospitalar" e "Higienização", nos idiomas português e inglês e indexados no Descritores em Ciências da Saúde (DeCS), os quais poderiam ser encontrados no título e/ou resumo. No que tange, aos critérios de exclusão, se desconsiderou trabalhos com metodologias diferentes ao levantamento bibliográfico, submissões duplicadas, artigos incompletos ou apenas resumos disponíveis e redundância dos critérios.

Esquema 1 - Organograma do processo de seleção dos artigos para este estudo.

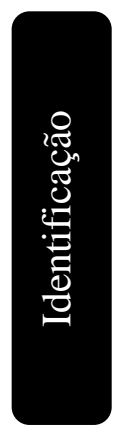

\begin{tabular}{|c|c|c|c|}
\hline $\begin{array}{c}\text { Estudos } \\
\text { selecionados do } \\
\text { LILACS }\end{array}$ & $\begin{array}{c}\text { Estudos } \\
\text { selecionados do } \\
\text { SciELO }\end{array}$ & $\begin{array}{c}\text { Estudos } \\
\text { selecionados do } \\
\text { Pubmed }\end{array}$ & $\begin{array}{c}\text { Estudos } \\
\text { selecionados do } \\
\text { Google scholar }\end{array}$ \\
\hline
\end{tabular}

Soma dos estudos que restaram após a retirada dos duplicados $=51$
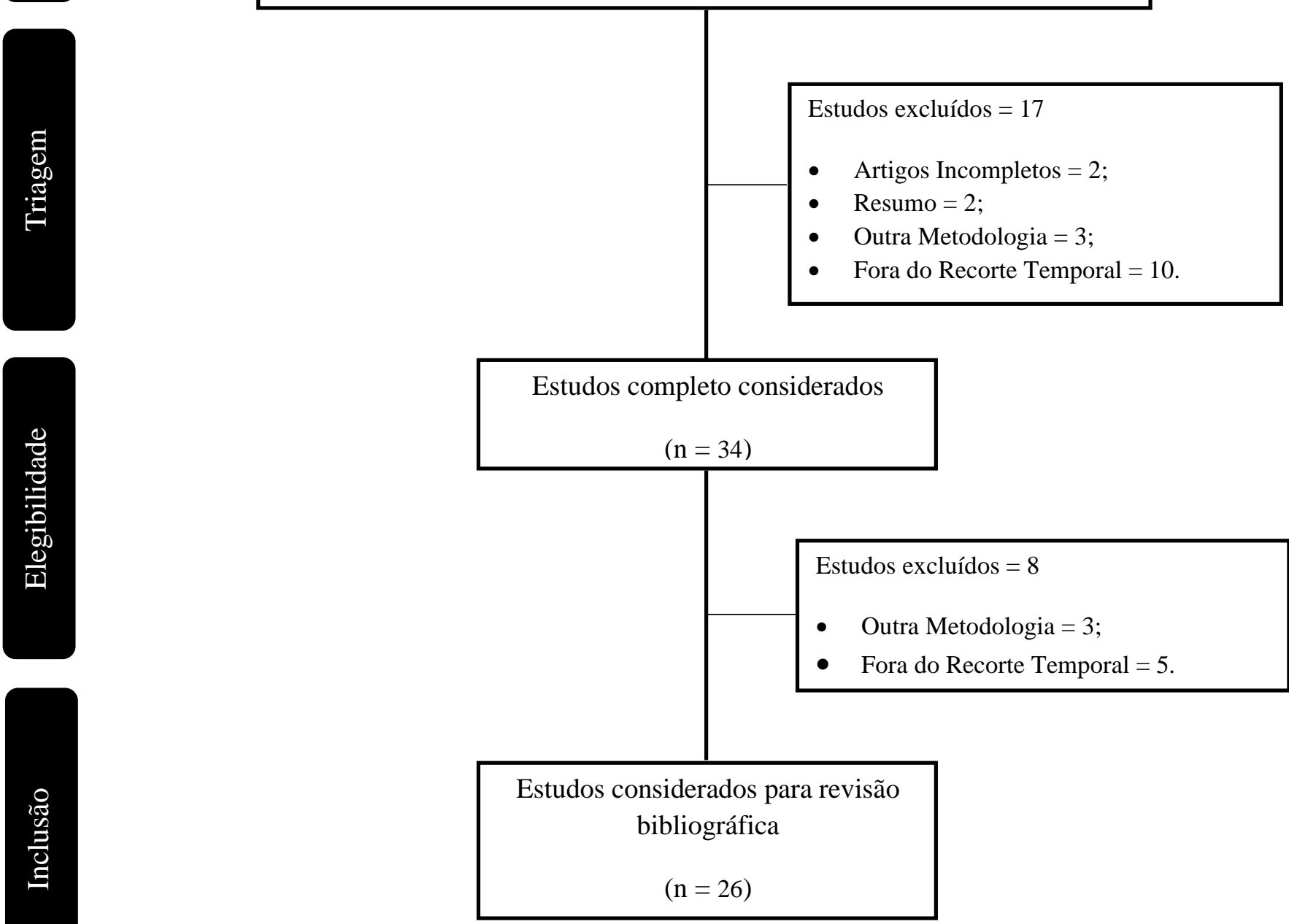

Fonte: Pesquisa Direta (2020). 


\section{Resultados}

Infecção hospitalar é aquela diagnosticada após 48 horas da internação do paciente. Através do raciocínio crítico, a enfermagem pode evitar que uma infecção se desenvolva ou se dissemine, minimizando a quantidade e os tipos de organismos transmitidos. Para isso é fundamental a disseminação de estudos que abordem o papel desse profissional diante das estratégias de segurança dos pacientes, sendo isso demostrado nas tabelas abaixo.

O total de estudos incluídos neste trabalho foi de 26 artigos, no recorte temporal, representado a Tabela 1, estimando o maior percentual contabilizado de produções sobre o tema com 30,77\% no ano de 2016 , acompanhado de $26,92 \%$ no ano de 2017, seguido de 15,38\%, 11,54\% e 19,23\% encontrados simultaneamente nos anos de 2018, 2019 e 2020.

Tabela 1 - Estudos incluídos no acervo, de acordo com o ano de publicação.

\begin{tabular}{ccc}
\hline Ano do periódico & Número de estudos & Porcentagem \\
2016 & 8 & $30,77 \%$ \\
2017 & 7 & $26,92 \%$ \\
2018 & 4 & $15,38 \%$ \\
2019 & 2 & $11,54 \%$ \\
2020 & 5 & $19,23 \%$ \\
TOTAL & $\mathbf{2 6}$ & $\mathbf{1 0 0 \%}$ \\
\hline
\end{tabular}

Fonte: Pesquisa direta (2020).

Dessa forma, na Tabela 2, as publicações da Revista Texto \& Contexto-Enfermagem correspondeu a porcentagem de 23,08\%, seguida da Revista Temas em Saúde, Revista de Enfermagem UFPE On-Line, Revista Saúde em Foco e Editora FIOCRUZ com 11,54\%, além da Revista Hospitais Universitários Federais e Universidade Federal de Mato Grosso com 7,69\%, acompanhadas da Faculdade INESP, Faculdade INESP, Revista Família, Ciclos de Vida e Saúde no Contexto Social e Caderno de Graduação-Ciências Biológicas e da Saúde representando 3,85\%.

Tabela 2 - Organização dos estudos incluídos no acervo, de acordo com o ano de publicação.

\begin{tabular}{lcc}
\hline \multicolumn{1}{c}{ NOME DO PERIÓDICO } & NÚMERO DE ESTUDOS & PORCENTAGEM \\
Revista Texto \& Contexto-Enfermagem & 06 & $23,08 \%$ \\
Revista Temas em Saúde & 03 & $11,54 \%$ \\
Revista de Enfermagem UFPE On-Line & 03 & $11,54 \%$ \\
Revista Saúde em Foco & 03 & $11,54 \%$ \\
Editora FIOCRUZ & 03 & $11,54 \%$ \\
Hospitais Universitários Federais & 02 & $7,69 \%$ \\
Revista Científica de Enfermagem & 02 & $7,69 \%$ \\
Universidade Federal de Mato Grosso & 01 & $3,85 \%$ \\
Faculdade INESP & 01 & $3,85 \%$ \\
Revista Família, Ciclos de Vida e Saúde no & 01 & $3,85 \%$ \\
Contexto Social & & $3,85 \%$ \\
Caderno de Graduação-Ciências Biológicas e & 01 & $\mathbf{1 0 0 \%}$ \\
da Saúde & & $\mathbf{2 6}$ \\
\hline \multicolumn{1}{c}{ TOTAL } & &
\end{tabular}

Fonte: Pesquisa direta (2020).

Em seguida a seleção inicial e descarte dos artigos duplicados, restaram 51. Além disso, foram retirados 34, os quais não se enquadravam aos critérios de inclusão pré-estabelecidos, com isso, dentre os 34 restantes que foram consultados na íntegra, 26 atenderam as exigências do estudo, através de uma metanálise.

No que tange a sinopse das 26 amostras selecionadas, com isso, a Tabela 3 contém a identificação dos artigos pelos autores, objetivos do estudo, tipo de amostragem, metodologia de pesquisa, análise dos resultados e considerações científicas. 
Tabela 3 - Sinopse dos estudos selecionados.

\begin{tabular}{|c|c|c|c|c|c|}
\hline Autores & Objetivos & Amostra & Estudo/Método & Resultados & Considerações \\
\hline $\begin{array}{l}\text { Luciele } \\
\text { Chaves, et } \\
\text { al. }\end{array}$ & $\begin{array}{l}\text { Discutir teoricamente } \\
\text { acerca da implantação } \\
\text { do serviço de } \\
\text { governança em } \\
\text { higiene e limpeza } \\
\text { hospitalar } \\
\text { identificando } \\
\text { possibilidades, } \\
\text { limitações e desafios } \\
\text { da atuação gerencial } \\
\text { do enfermeiro nesse } \\
\text { serviço. }\end{array}$ & 15 estudos & $\begin{array}{l}\text { Revisão sistêmica } \\
\text { da bibliográfica } \\
\text { integrativa. }\end{array}$ & $\begin{array}{l}\text { Destaca-se que a } \\
\text { possibilidade de } \\
\text { contribuição do } \\
\text { enfermeiro na busca por } \\
\text { um sistema de governança } \\
\text { único para diferentes } \\
\text { contextos dos sistemas de } \\
\text { apoio clínico, } \\
\text { administrativo e logístico, } \\
\text { com ênfase no } \\
\text { gerenciamento de pessoas. }\end{array}$ & $\begin{array}{l}\text { Novos campos de atuação } \\
\text { são propostos no serviço de } \\
\text { governança em higiene e } \\
\text { limpeza hospitalar, enquanto } \\
\text { estratégia de gestão do } \\
\text { cuidado e de serviço, além } \\
\text { de desafio para o } \\
\text { profissional enfermeiro. }\end{array}$ \\
\hline $\begin{array}{l}\text { Hélio } \\
\text { Silva, et } \\
\text { al. }\end{array}$ & $\begin{array}{l}\text { Formalizar a } \\
\text { padronização do } \\
\text { Serviço de } \\
\text { Higienização } \\
\text { Hospitalar no } \\
\text { Hospital de Clínicas } \\
\text { da Universidade } \\
\text { Federal do Triângulo } \\
\text { Mineiro. }\end{array}$ & 02 estudos & $\begin{array}{l}\text { Revisão sistêmica } \\
\text { da bibliográfica } \\
\text { com metanálise. }\end{array}$ & $\begin{array}{l}\text { Acondicionar, transportar } \\
\text { e dispor o resíduo } \\
\text { hospitalar requer cuidados } \\
\text { especiais, uma vez que as } \\
\text { operações impróprias ou } \\
\text { inadequadas, bem como a } \\
\text { presença de insetos e } \\
\text { roedores acabarão por } \\
\text { disseminar doenças } \\
\text { infectocontagiosas. }\end{array}$ & $\begin{array}{l}\text { Todas as etapas do trato com } \\
\text { o resíduo hospitalar são } \\
\text { importantes, iniciando-se } \\
\text { pela segregação, transporte } \\
\text { correto e depósitos } \\
\text { apropriados, enquanto } \\
\text { aguarda a operação de coleta } \\
\text { municipal, conforme consta } \\
\text { no PGRSS desta instituição. }\end{array}$ \\
\hline $\begin{array}{l}\text { Carlos } \\
\text { Cunha e } \\
\text { Leonardo } \\
\text { Carnut }\end{array}$ & $\begin{array}{l}\text { Relatar práticas e } \\
\text { saberes voltados para } \\
\text { a promoção, proteção } \\
\text { e recuperação da } \\
\text { saúde das populações, } \\
\text { respeitando suas } \\
\text { diversidades }\end{array}$ & 35 estudos & $\begin{array}{l}\text { Revisão sistêmica } \\
\text { da bibliográfica } \\
\text { integrativa. }\end{array}$ & $\begin{array}{l}\text { Problematização e } \\
\text { informação sobre as bases } \\
\text { e o processo da Reforma } \\
\text { Sanitária, relatando os } \\
\text { limites e avanços, } \\
\text { deficiências e perspectivas } \\
\text { nas políticas de saúde. }\end{array}$ & $\begin{array}{l}\text { Congregar o mais refinado } \\
\text { aporte teórico em saúde } \\
\text { coletiva e assumir a tarefa } \\
\text { de formar futuros } \\
\text { profissionais devidamente } \\
\text { preocupados com as } \\
\text { iniquidades que se } \\
\text { expressam no setor, e } \\
\text { dispostos a garantir o direito } \\
\text { à saúde como um elemento } \\
\text { indissociável do conceito de } \\
\text { justiça social. }\end{array}$ \\
\hline $\begin{array}{l}\text { Lorena } \\
\text { Moura, et } \\
\text { al. }\end{array}$ & $\begin{array}{l}\text { Identificar a } \\
\text { relevância da higiene } \\
\text { e desinfecção do } \\
\text { mobiliário e da } \\
\text { unidade hospitalar na } \\
\text { segurança do paciente }\end{array}$ & 15 estudos & $\begin{array}{l}\text { Revisão } \\
\text { bibliográfica da } \\
\text { literatura nacional. }\end{array}$ & $\begin{array}{l}\text { Demonstra a importância } \\
\text { de discutir sobre a } \\
\text { incidência das infecções } \\
\text { hospitalares como um } \\
\text { problema crescente de } \\
\text { saúde pública. }\end{array}$ & $\begin{array}{l}\text { Evidencia-se a necessidade } \\
\text { de colocar em prática } \\
\text { estratégias que garantam a } \\
\text { prevenção de tais infecções } \\
\text { e o rigoroso controle das } \\
\text { mesmas, quando vierem a } \\
\text { ocorrer no âmbito hospitalar } \\
\text { e demais instituições de } \\
\text { saúde. }\end{array}$ \\
\hline $\begin{array}{l}\text { Patrícia } \\
\text { Potter, et } \\
\text { al. }\end{array}$ & $\begin{array}{l}\text { Oferecer uma } \\
\text { abordagem } \\
\text { contemporânea à } \\
\text { prática de } \\
\text { enfermagem, } \\
\text { discutindo todo o } \\
\text { escopo de cuidados } \\
\text { primários, agudos e } \\
\text { restauradores. }\end{array}$ & 50 estudos & $\begin{array}{l}\text { Revisão sistêmica } \\
\text { da bibliográfica } \\
\text { integrativa. }\end{array}$ & $\begin{array}{l}\text { A equipe de enfermagem } \\
\text { tem importante papel na } \\
\text { manutenção dos artigos } \\
\text { hospitalares de sua } \\
\text { unidade de trabalho, seja } \\
\text { em ambulatórios, } \\
\text { unidades básicas ou } \\
\text { outros setores em que } \\
\text { esteja atuando. }\end{array}$ & $\begin{array}{l}\text { Deve-se considerar as } \\
\text { necessidades de consumo, as } \\
\text { condições de } \\
\text { armazenamento, a validade } \\
\text { dos produtos e o prazo de } \\
\text { esterilização. }\end{array}$ \\
\hline
\end{tabular}




\begin{tabular}{|c|c|c|c|c|c|}
\hline $\begin{array}{l}\text { Maria } \\
\text { Prestes }\end{array}$ & $\begin{array}{l}\text { Compreender os } \\
\text { conceitos básicos } \\
\text { sobre a ciência, o } \\
\text { método científico } \\
\text { para a elaboração de } \\
\text { textos e pesquisa, } \\
\text { obedecendo ao que } \\
\text { rezam as normas da } \\
\text { ABNT. }\end{array}$ & 39 estudos & $\begin{array}{l}\text { Revisão sistêmica } \\
\text { da bibliográfica } \\
\text { integrativa. }\end{array}$ & $\begin{array}{l}\text { A ciência é capaz de } \\
\text { fornecer respostas dignas } \\
\text { de confiança sujeitas a } \\
\text { críticas; é uma forma de } \\
\text { entender, compreender os } \\
\text { fenômenos que ocorrem. }\end{array}$ & $\begin{array}{l}\text { Trata-se do estudo, com } \\
\text { critérios metodológicos, das } \\
\text { relações existentes entre } \\
\text { causa e efeito de um } \\
\text { fenômeno qualquer no qual } \\
\text { o estudioso se propõe a } \\
\text { demonstrar a verdade dos } \\
\text { fatos e suas aplicações } \\
\text { práticas. }\end{array}$ \\
\hline $\begin{array}{l}\text { Jose } \\
\text { Aragão }\end{array}$ & $\begin{array}{l}\text { Conhecer a } \\
\text { concepção que os } \\
\text { enfermeiros de uma } \\
\text { instituição hospitalar } \\
\text { pública e de ensino } \\
\text { têm sobre os } \\
\text { pressupostos } \\
\text { ambientais de } \\
\text { Florence Nightingale. }\end{array}$ & $\begin{array}{l}08 \text { enfermeiros } \\
\text { assistenciais. }\end{array}$ & $\begin{array}{l}\text { Estudo descritivo, } \\
\text { exploratório, de } \\
\text { abordagem } \\
\text { qualitativa. }\end{array}$ & $\begin{array}{l}\text { Os enfermeiros } \\
\text { consideram as condições } \\
\text { de higiene, alimentação, } \\
\text { acomodação e qualidade } \\
\text { do ar oferecidas aos } \\
\text { pacientes e equipe } \\
\text { profissional em seu atuar } \\
\text { correspondentes aos } \\
\text { pressupostos ambientais } \\
\text { nightingaleanos, mesmo } \\
\text { não tendo um } \\
\text { conhecimento sólido da } \\
\text { teoria nightingaleana e de } \\
\text { sua utilidade para a } \\
\text { prática profissional. }\end{array}$ & $\begin{array}{l}\text { Faz-se necessário um } \\
\text { processo educativo } \\
\text { permanente para suprir essa } \\
\text { lacuna de desconhecimento. }\end{array}$ \\
\hline $\begin{array}{l}\text { Andreia } \\
\text { Cazali }\end{array}$ & $\begin{array}{l}\text { Estudar em que } \\
\text { consiste a } \\
\text { higienização das } \\
\text { mãos, sua } \\
\text { contribuição na } \\
\text { prevenção e controle } \\
\text { das infecções no } \\
\text { âmbito hospitalar, as } \\
\text { técnicas e } \\
\text { procedimentos para } \\
\text { sua realização e os } \\
\text { fatores que interferem } \\
\text { na adesão de } \\
\text { profissionais de saúde } \\
\text { ao uso dessa } \\
\text { ferramenta. }\end{array}$ & 16 estudos & $\begin{array}{l}\text { Estudo } \\
\text { bibliográfico. }\end{array}$ & $\begin{array}{l}\text { A aplicação de produtos } \\
\text { antissépticos, } \\
\text { especialmente com base } \\
\text { alcoólica, pode reduzir } \\
\text { ainda mais os riscos de } \\
\text { transmissão, ela } \\
\text { intensificação da redução } \\
\text { microbiana ou } \\
\text { favorecendo um aumento } \\
\text { na frequência de } \\
\text { higienização das mãos, } \\
\text { uma potente ferramenta } \\
\text { para a prevenção de } \\
\text { infecções hospitalares. }\end{array}$ & $\begin{array}{l}\text { Implica o domínio do } \\
\text { conhecimento acerca dos } \\
\text { benefícios e técnicas } \\
\text { corretas de lavagem das } \\
\text { mãos, para que ocorra uma } \\
\text { maior adesão dos } \\
\text { profissionais. }\end{array}$ \\
\hline $\begin{array}{l}\text { Luciele } \\
\text { Chaves }\end{array}$ & $\begin{array}{l}\text { Discutir e refletir } \\
\text { teoricamente acerca } \\
\text { do serviço de } \\
\text { governança em } \\
\text { higiene e limpeza } \\
\text { hospitalar, } \\
\text { identificando } \\
\text { possibilidades, } \\
\text { limitações e desafios } \\
\text { da atuação gerencial } \\
\text { do enfermeiro. }\end{array}$ & 15 estudos & Estudo reflexivo. & $\begin{array}{l}\text { A implantação desse } \\
\text { serviço apresenta } \\
\text { potencialidades como } \\
\text { agilidade na realização da } \\
\text { limpeza de unidade, } \\
\text { dimensionamento da } \\
\text { reposição do quadro de } \\
\text { pessoal em instituições } \\
\text { públicas com a } \\
\text { terceirização de } \\
\text { trabalhadores, além de } \\
\text { adequação do } \\
\text { dimensionamento, } \\
\text { aspectos que repercutem } \\
\text { na segurança do usuário. }\end{array}$ & $\begin{array}{l}\text { As limitações dizem respeito } \\
\text { à capacitação de recursos } \\
\text { humanos e adequação de } \\
\text { atuação no cenário } \\
\text { hospitalar, visto que este } \\
\text { serviço representa espaço de } \\
\text { atuação gerencial do } \\
\text { enfermeiro. }\end{array}$ \\
\hline
\end{tabular}




\begin{tabular}{ll}
\hline Amanda & Identificar a \\
Floriano & contribuição dos fatos \\
& e escritos de Florence \\
& Nightingale nos \\
& artigos publicados \\
& entre os anos de 2004 \\
& e 2011, na percepção \\
& dos autores.
\end{tabular}

$\begin{array}{ll}\text { Isa } & \text { Atualizar o } \\ \text { Silveira, et } & \text { conhecimento a } \\ \text { al. } & \text { respeito dos aspectos } \\ & \text { microbiológicos da } \\ & \text { cavidade oral e a } \\ & \text { relação com a higiene } \\ & \text { bucal na prevenção da } \\ & \text { pneumonia associada } \\ & \text { à ventilação } \\ & \text { mecânica. }\end{array}$

Anelvira Apresentar as taxas

Florentino, de infecção geral

et al mensuradas antes e

33 estudos

Revisão integrativa

da literatura.

Os resultados indicam que

Nightingale, como pessoa

pública, é objeto de

comentários polêmicos

sobre sua vida e profissão.

24 estudos

Revisão sistêmica
da bibliográfica
integrativa.

Tradicionalmente, a

higiene bucal compõe a

higiene corporal como um

todo e constitui um dos

mais importantes cuidados

de enfermagem.
Conclui-se que seus feitos e escritos influenciaram diversas áreas além da enfermagem, como estatística, administração em saúde, saúde pública, fisioterapia e espiritualidade.

Assim, faz-se necessária a divulgação e atualização sobre a temática, a fim de oferecer maior capacitação durante a assistência aos pacientes. depois da intervenção em um hospital privado em

\section{Estudo descritivo exploratório com abordagem quantitativa e qualitativa. \\ A taxa de IRAS variou de $5,0 \%$ a $4,0 \%$ durante o ano 2017 com uma média de $3,58 \%$ e em 2018 com queda para $2,07 \%$.}

Itapetininga/SP.

\section{As IRAS poderiam ser evitadas com medidas simples de busca ativa. Este tipo de ação mostrou a importância do controle diário e orientação in loco, reforçando, a importância da higiene das mãos e o cumprimento dos cinco momentos conforme a OMS.}

\begin{tabular}{|c|c|c|}
\hline $\begin{array}{l}\text { Rosana } \\
\text { Haddad, et } \\
\text { al. }\end{array}$ & $\begin{array}{l}\text { Avaliar a técnica de } \\
\text { higiene das mãos e a } \\
\text { eficácia de dois } \\
\text { degermante, sendo } \\
\text { um de uso regular em } \\
\text { hospitais e outro à } \\
\text { base de óleo de } \\
\text { rícino. }\end{array}$ & $\begin{array}{l}16 \text { voluntários } \\
\text { graduandos de } \\
\text { Enfermagem, } \\
\text { Biologia e } \\
\text { Medicina } \\
\text { Veterinária da } \\
\text { Universidade } \\
\text { Estadual do } \\
\text { Norte do } \\
\text { Paraná. }\end{array}$ \\
\hline
\end{tabular}

\section{O procedimento de higiene das mãos é fundamental para o controle e prevenção de infecção hospitalar. \\ A lavagem das mãos realizadas na Técnica ene das mãos corn entou diferen} significativa na redução dos micro-organismos, comparado ao degermante utilizado, que foi superior a $90 \%$, porém o não emprego correto da técnica de higiene das mãos para a redução de micro-organismos foi significativamente menor, $35 \%$ e $60 \%$.

$\begin{array}{ll}\text { Lorena } & \text { Evidenciar a } \\ \text { Moura, et } & \text { relevância da } \\ \text { al. } & \text { higienização nas } \\ & \text { ações assistenciais, } \\ & \text { desinfecção do } \\ & \text { mobiliário e da } \\ & \text { unidade hospitalar } \\ & \text { como estratégia de } \\ \text { garantia da segurança } & \text { do paciente. }\end{array}$

\section{5 estudos}

da bibliográfica
integrativa.

\section{Pelo perfil profissional que coloca o enfermeiro em relação direta com o paciente, cabe a ele cuidar para que os profissionais de enfermagem combatam as infecções hospitalares com medias de prevenção e controle.}

Logo, enfermeiro é o principal agente de disseminação do conhecimento sobre a higienização, desinfecção correta do ambiente para combater um grave problema de saúde pública que representam as infecções hospitalares. 


\begin{tabular}{|c|c|c|c|c|c|}
\hline $\begin{array}{l}\text { Joathan } \\
\text { Ribeiro, et } \\
\text { al. }\end{array}$ & $\begin{array}{l}\text { Identificar os } \\
\text { procedimentos a } \\
\text { serem seguidos para a } \\
\text { higienização } \\
\text { hospitalar, comparar a } \\
\text { condição } \\
\text { microbiológica antes } \\
\text { e depois da } \\
\text { higienização. }\end{array}$ & 15 estudos & $\begin{array}{l}\text { Revisão sistêmica } \\
\text { da bibliográfica } \\
\text { integrativa. }\end{array}$ & $\begin{array}{l}\text { A percepção acerca da } \\
\text { frequência para realização } \\
\text { de procedimentos } \\
\text { destinados a uma correta } \\
\text { higienização hospitalar } \\
\text { que se estabelecerá de } \\
\text { acordo com área de } \\
\text { acordo com a área a qual } \\
\text { visa eliminar toda a } \\
\text { sujidade e os } \\
\text { microrganismos que } \\
\text { podem desencadear } \\
\text { infecções. }\end{array}$ & $\begin{array}{l}\text { Concluímos que apenas com } \\
\text { a higienização não é } \\
\text { possível extinguir o risco de } \\
\text { infecções hospitalares, mas } \\
\text { não se pode deixar de levar } \\
\text { em consideração a parcela } \\
\text { de responsabilidade } \\
\text { relacionada aos padrões de } \\
\text { assepsia e de higiene do } \\
\text { ambiente hospitalar. }\end{array}$ \\
\hline $\begin{array}{l}\text { Vandilson } \\
\text { Rodrigues, } \\
\text { et al. }\end{array}$ & $\begin{array}{l}\text { Avaliar os hábitos de } \\
\text { higiene bucal } \\
\text { empregados por } \\
\text { crianças durante o } \\
\text { período de internação } \\
\text { hospitalar, a fim de } \\
\text { orientar na } \\
\text { formulação de } \\
\text { estratégias para } \\
\text { abordagem da saúde } \\
\text { bucal neste espaço } \\
\text { diferenciado. }\end{array}$ & 91 crianças & $\begin{array}{l}\text { Estudo } \\
\text { observacional de } \\
\text { corte transversal. }\end{array}$ & $\begin{array}{l}\text { As práticas de higiene } \\
\text { bucal durante o período de } \\
\text { hospitalização, observou- } \\
\text { se o predomínio do } \\
\text { cuidador como o } \\
\text { responsável por realizar a } \\
\text { higiene bucal da criança } \\
\text { ( } 75,4 \%) \text {, reforçando a } \\
\text { importância de medidas } \\
\text { de promoção e prevenção } \\
\text { de saúde pelo público } \\
\text { infantil. }\end{array}$ & $\begin{array}{l}\text { Os resultados sugerem a } \\
\text { necessidade de se } \\
\text { problematizar a abordagem } \\
\text { da promoção de saúde bucal } \\
\text { em ambiente hospitalar. }\end{array}$ \\
\hline $\begin{array}{l}\text { Nayara } \\
\text { Soares, et } \\
\text { al. }\end{array}$ & $\begin{array}{l}\text { Avaliar os } \\
\text { conhecimentos, } \\
\text { atitudes e práticas da } \\
\text { equipe de } \\
\text { enfermagem sobre } \\
\text { higienização das } \\
\text { mãos. }\end{array}$ & $\begin{array}{l}135 \\
\text { profissionais de } \\
\text { enfermagem de } \\
\text { um hospital } \\
\text { universitário }\end{array}$ & $\begin{array}{l}\text { Estudo seccional, } \\
\text { de abordagem } \\
\text { quantitativa. }\end{array}$ & $\begin{array}{l}\text { Os dados foram } \\
\text { submetidos à análise } \\
\text { descritiva univariada. } \\
\text { Todos os participantes da } \\
\text { investigação (100\%) } \\
\text { acreditam que a HM é um } \\
\text { procedimento importante } \\
\text { na prevenção de infecção } \\
\text { e mais de } 50 \% \\
\text { consideram a sobrecarga } \\
\text { de trabalho e o número } \\
\text { reduzido de dispensadores } \\
\text { de álcool gel como } \\
\text { obstáculos à HM na } \\
\text { prática clínica diária. }\end{array}$ & $\begin{array}{l}\text { A criação de parcerias com } \\
\text { o Serviço de Educação em } \\
\text { Enfermagem (SEE) e } \\
\text { Comissão de Controle de } \\
\text { Infecção Hospitalar da } \\
\text { instituição de estudo são } \\
\text { considerados facilitadores } \\
\text { para que os profissionais } \\
\text { aprimorem os } \\
\text { conhecimentos e esclareçam } \\
\text { dúvidas sobre HM. }\end{array}$ \\
\hline $\begin{array}{l}\text { Eliane } \\
\text { Souza, et } \\
\text { al. }\end{array}$ & $\begin{array}{l}\text { Analisar o } \\
\text { conhecimento dos } \\
\text { acadêmicos de } \\
\text { enfermagem sobre o } \\
\text { procedimento de } \\
\text { higienização das } \\
\text { mãos. }\end{array}$ & $\begin{array}{l}43 \text { e } 36 \\
\text { estudantes do } \\
\text { primeiro e nono } \\
\text { período } \\
\text { respectivamente } \\
\text { do curso de } \\
\text { enfermagem. }\end{array}$ & $\begin{array}{l}\text { Estudo seccional, } \\
\text { de abordagem } \\
\text { quantitativa. }\end{array}$ & $\begin{array}{l}\text { Das } 8 \text { questões } \\
\text { disponibilizadas para } \\
\text { avaliar o conhecimento } \\
\text { dos estudantes acerca da } \\
\text { higienização das mãos. } \\
100 \% \text { (n=8) tiveram } \\
\text { maior índice de respostas } \\
\text { corretas pelos alunos de } \\
\text { enfermagem do } 9^{\circ} \\
\text { período. }\end{array}$ & $\begin{array}{l}\text { Conclui-se que os alunos } \\
\text { que iniciam a graduação } \\
\text { podem ter noção de higiene, } \\
\text { mas, não possuem as } \\
\text { técnicas relacionadas a este } \\
\text { procedimento, em } \\
\text { contrapartida os alunos do } \\
\text { último período já obtiveram } \\
\text { informações necessárias } \\
\text { para executá-lo da maneira } \\
\text { recomendada. }\end{array}$ \\
\hline $\begin{array}{l}\text { Karen } \\
\text { Trannin, et } \\
\text { al. }\end{array}$ & $\begin{array}{l}\text { Observar a adesão à } \\
\text { higiene das mãos por } \\
\text { profissionais de saúde } \\
\text { de um Serviço de } \\
\text { Emergência de } \\
\text { Hospital }\end{array}$ & 30 estudos & $\begin{array}{l}\text { Pesquisa } \\
\text { qualitativa. }\end{array}$ & $\begin{array}{l}\text { Observou-se adesão de } \\
28,6 \% \text { para } 38,9 \% \text { após as } \\
\text { ações educativas. Na fase } \\
\text { pós-intervenção, todos os } \\
\text { profissionais } \\
\text { apresentaram maior }\end{array}$ & $\begin{array}{l}\text { Conclui-se que a } \\
\text { higienização das mãos } \\
\text { esteve aquém do esperado e } \\
\text { que estratégias educativas } \\
\text { favoreceram a adesão. }\end{array}$ \\
\hline
\end{tabular}




\begin{tabular}{ll}
\hline Universitário, no & adesão à higiene das mãos \\
estado de São Paulo. & quando comparado ao \\
& período pré-intervenção e \\
& a adesão foi \\
& significativamente maior \\
& após a realização de \\
& procedimentos assépticos.
\end{tabular}

$\begin{array}{llll}\text { Anne } & \text { Prevenir danos à } & 77 \text { estudos } & \begin{array}{l}\text { Revisão sistêmica } \\ \text { da bibliográfica }\end{array} \\ \text { Perry e } & \text { saúde das pessoas ou } & & \text { integrativa. } \\ \text { Patrícia } & \text { de restabelecê-la, } & & \end{array}$

Os materiais necessários à execução dos

de restabelecê-la, procedimentos devem ser reunidos e levados numa cuidados dispensados.

bandeja para junto do paciente, e o ambiente devidamente preparado para evitar idas e vindas desnecessárias e a impressão de desleixo.

\begin{tabular}{|c|c|c|c|c|c|}
\hline $\begin{array}{l}\text { Jéssica } \\
\text { Campos e } \\
\text { Olgair } \\
\text { Almeida }\end{array}$ & $\begin{array}{l}\text { Controlar as } \\
\text { infecções } \\
\text { relacionadas à } \\
\text { assistência à saúde. }\end{array}$ & 15 estudos & $\begin{array}{l}\text { Revisão sistêmica } \\
\text { da bibliográfica } \\
\text { integrativa. }\end{array}$ & $\begin{array}{l}\text { O Serviço de Limpeza e } \\
\text { Desinfecção de } \\
\text { Superfícies em Serviços } \\
\text { de Saúde apresenta } \\
\text { relevante papel na } \\
\text { prevenção das infecções } \\
\text { relacionadas à assistência } \\
\text { à saúde, sendo } \\
\text { imprescindível o } \\
\text { aperfeiçoamento do uso } \\
\text { de técnicas eficazes para } \\
\text { promover a limpeza e } \\
\text { desinfecção de } \\
\text { superfícies. }\end{array}$ & $\begin{array}{l}\text { A proposta deste trabalho é } \\
\text { apresentar alguns estudos } \\
\text { que evidenciam a } \\
\text { problemática da } \\
\text { contaminação do ambiente } \\
\text { como determinante na } \\
\text { disseminação de agentes } \\
\text { infecciosos nos serviços de } \\
\text { saúde. }\end{array}$ \\
\hline $\begin{array}{l}\text { Clarissa } \\
\text { Bezerra, et } \\
\text { al. }\end{array}$ & $\begin{array}{l}\text { Descrever a teoria } \\
\text { ambientalista de } \\
\text { Florence Nightingale } \\
\text { com base no modelo } \\
\text { de avaliação de } \\
\text { Meleis. }\end{array}$ & 20 estudos & $\begin{array}{l}\text { Estudo teórico } \\
\text { reflexivo. }\end{array}$ & $\begin{array}{l}\text { A teoria apresenta } \\
\text { conceitos de ser humano, } \\
\text { ambiente, saúde e } \\
\text { enfermagem, tendo como } \\
\text { foco principal o controle } \\
\text { do meio ambiente. A ação } \\
\text { do enfermeiro no trato do } \\
\text { enfermo implementada } \\
\text { dentro de um ambiente } \\
\text { saudável constitui sua } \\
\text { principal proposição para } \\
\text { a enfermagem. }\end{array}$ & $\begin{array}{l}\text { A teoria ambientalista é } \\
\text { uma teoria usual e sempre } \\
\text { atual, não apenas pelo que é } \\
\text { descrito sobre a higiene, } \\
\text { micro-organismos, sujidades } \\
\text { e no tratamento dos doentes, } \\
\text { mas pela aplicabilidade na } \\
\text { prática de enfermagem com } \\
\text { relação ao ser humano, } \\
\text { ambiente e saúde. }\end{array}$ \\
\hline $\begin{array}{l}\text { Lourena } \\
\text { Borson, et } \\
\text { al. }\end{array}$ & $\begin{array}{l}\text { Exibir a teoria } \\
\text { ambiental de Florence } \\
\text { Nightingale. }\end{array}$ & 07 estudos & $\begin{array}{l}\text { Pesquisa cientifica } \\
\text { em artigos online e } \\
\text { livros da área. }\end{array}$ & $\begin{array}{l}\text { Uma breve história da } \\
\text { vida de Florence; o que } \\
\text { acontece posteriormente } \\
\text { seu trabalho na guerra da } \\
\text { Crimeia, destacando o } \\
\text { prêmio recebido que foi } \\
\text { de grande importância } \\
\text { para abrir sua primeira } \\
\text { escola de enfermagem, } \\
\text { seguindo da apresentação } \\
\text { de sua famosa teoria, a } \\
\text { Teoria Ambiental. }\end{array}$ & $\begin{array}{l}\text { Se tem a conclusão da } \\
\text { importância da ação de um } \\
\text { meio ambiente saudável no } \\
\text { desenvolvimento da cura de } \\
\text { um doente/indivíduo. }\end{array}$ \\
\hline
\end{tabular}




\begin{tabular}{|c|c|c|c|c|c|}
\hline $\begin{array}{l}\text { Denyse } \\
\text { Martins, et } \\
\text { al. }\end{array}$ & $\begin{array}{l}\text { Entender que as } \\
\text { falhas nos processos } \\
\text { de limpeza e } \\
\text { desinfecção de } \\
\text { superfícies podem ter } \\
\text { como consequência a } \\
\text { disseminação e a } \\
\text { transferência de } \\
\text { microrganismos do } \\
\text { ambiente para o } \\
\text { paciente. }\end{array}$ & 20 estudos & $\begin{array}{l}\text { Revisão sistêmica } \\
\text { da bibliográfica } \\
\text { com metanálise. }\end{array}$ & $\begin{array}{l}\text { O conteúdo desse POP } \\
\text { busca sistematizar o } \\
\text { serviço de higienização } \\
\text { hospitalar, com a } \\
\text { finalidade de colaborar } \\
\text { com a segurança do } \\
\text { cliente e profissional e } \\
\text { melhorar a qualidade do } \\
\text { serviço, bem como } \\
\text { cumprir com as } \\
\text { necessidades para } \\
\text { acreditação da instituição. }\end{array}$ & $\begin{array}{l}\text { Diante disso, sentimos a } \\
\text { necessidade de elaborar um } \\
\text { protocolo para padronizar e } \\
\text { adequar as atividades a } \\
\text { serem executadas no } \\
\text { Hospital Universitário Lauro } \\
\text { Wanderley, utilizando } \\
\text { produtos e materiais de } \\
\text { acordo com a legislação } \\
\text { sanitária vigente. }\end{array}$ \\
\hline $\begin{array}{l}\text { Nelson } \\
\text { Grisard e } \\
\text { Edith } \\
\text { Vierira }\end{array}$ & $\begin{array}{l}\text { homenagear a } \\
\text { precursora da } \\
\text { enfermagem no Brasil } \\
\text { e a participação de } \\
\text { alguns de seus alunos } \\
\text { e mestres na Guerra } \\
\text { do Paraguai. }\end{array}$ & 22 estudos & $\begin{array}{l}\text { Revisão sistêmica } \\
\text { da bibliográfica } \\
\text { com metanálise. }\end{array}$ & $\begin{array}{l}\text { Contemporâneas, muitas } \\
\text { são as semelhanças entre } \\
\text { Ana e Florence: ambas } \\
\text { ricas, estudadas, cultas e } \\
\text { poliglotas, severas e } \\
\text { disciplinadoras, } \\
\text { organizadas e dedicadas } \\
\text { com denodo às tarefas } \\
\text { autoimpostas em } \\
\text { benefício dos sofredores } \\
\text { das dores da guerra. }\end{array}$ & $\begin{array}{l}\text { O cuidado dos feridos, } \\
\text { inicialmente de forma } \\
\text { empírica e pouco a pouco de } \\
\text { forma sistematizada, levou-a } \\
\text { a adquirir segurança e } \\
\text { confiança, aprimorando } \\
\text { táticas de cuidados e criando } \\
\text { técnicas próprias no } \\
\text { atendimento. }\end{array}$ \\
\hline
\end{tabular}

Fonte: Pesquisa direta (2020).

\section{Discussão}

De um modo geral os artigos analisados convergem no sentido de que a equipe de enfermagem é essencial para o sucesso da manutenção da higiene nos setores hospitalares, sendo tal ato fundamental para a manutenção ou/e diminuição de danos à saúde do paciente (Haddad et al, 2016; Aragão, 2017; Ribeiro et al, 2017, Florentino et al, 2020, Tranin et al, 2016, Moura et al, 2017; Souza et al, 2017; Rodrigues et al, 2011; Silveira et al, 2010; Cazali et al, 2018; Floriano et al, 2020).

Entretanto, divergem no motivo das dificuldades encontradas para a implementação ou manutenção desta higienização, haja à vista, que alguns expõem que uma das causas principais para a ocorrência de infecções hospitalares advém da própria equipe de saúde que não realiza a assepsia de forma correta (Haddad et al, 2016; Aragão, 2017; Ribeiro et al, 2017; Florentino et al, 2020; Tranin et al, 2016; Moura et al, 2017).

Já outros, afirmam que o desconhecimento da família a respeito da qualidade e importância da higienização, a falta de apoio do paciente quando possível e a complicação natural do processo de adoecimento associado à hospitalização, decorrentes do desequilíbrio entre a microbiota endógena e mecanismos de defesa do organismo, podem isoladamente acarretar o processo de infecções hospitalares (Souza et al, 2017; Rodrigues et al, 2011; Silveira et al, 2010).

No que tange as limitações encontradas pelo estudo, reporta-se que a pesquisa apresentou barreiras relacionadas a quantidade de estudos encontrados, sendo evidente um déficit de publicações relacionadas ao tema proposto, considerando uma concentração de artigos acima do corte temporal de cinco anos, a escassez de literatura brasileira e a restrição da problemática a equipe de enfermagem, desconsiderando as demais classes de profissionais que também detém um papel importante na manutenção da higiene hospitalar.

\section{O papel da equipe de enfermagem no contexto da higiene hospitalar}

$\mathrm{O}$ trabalho do enfermeiro, normalmente, baseia-se nos cuidados com o indivíduo garantindo seu conforto e bem estar, exercendo funções na prevenção e controle de infecções, na coordenação da equipe de enfermagem e dentre outras atribuições 
que fazem com que este profissional seja o qual mais tenha contato com a população em geral, atuando sempre na linha de frente contra as mais diversas doenças (Floriano et al, 2020).

Com relação a higienização hospitalar estes profissionais no Brasil trabalha tanto na assistência e no cuidado com a assepsia do paciente, como ainda efetuam atividades de conscientização e educação em saúde acerca da utilização adequada de EPI's, na construção de áreas de isolamento e descanso, na prevenção de contaminação, na manutenção da segurança do paciente (Tranin et al, 2016).

Tais atribuições são encontradas no Decreto n $94405 / 1987$, que regulamenta a Lei do Exercício Profissional da Enfermagem, no qual reafirma que é de responsabilidade do enfermeiro a "Prevenção e controle sistemático da infecção hospitalar, inclusive como membro das respectivas comissões", além de que cabe ao mesmo participar da construção de medidas de prevenção e controle sistemático de danos que exponham o paciente a risco (Moura et al, 2017).

Destarte, a equipe de enfermagem pode evitar, por meio, da construção de protocolos e da realização correta das recomendações de higiene nacionais e internacionais, que uma infecção se desenvolva ou se dissemine, minimizando a quantidade e os tipos de organismos transmitidos para os potenciais sítios de transmissão. (Moura et al, 2017)

Portanto, a equipe de enfermagem desempenha importante papel no contexto da higienização hospitalar, sendo indiscutível a capacidade de gerenciamento do enfermeiro prevenção e controle de infecções, visando à garantia de qualidade na assistência e a segurança do paciente (Chaves et al, 2015).

\section{Desafios encontrados para a implementação ou manutenção da higiene hospitalar}

Segundo as teorias de Florence Nightingale e Ana Neri para uma cura completa e significativa do paciente é necessário que o meio que cerca este indivíduo, também seja favorável para manter a sua saúde. Nesse contexto, a melhoria das condições do ambiente hospitalar traz consigo o cuidado mais abrangente, que ver o cliente além da sua doença e sim como um todo (Floriano, 2020).

Entretanto, com base nos estudos encontrados observou-se que atualmente o ambiente hospital possui uma série de riscos que comprometem a saúde dos pacientes. Um deles, segundo a Organização Mundial da Saúde (OMS), são as infecções hospitalares que são infecções adquiridas durante o período hospitalização que representam um sério problema de saúde, sendo que constituem uma das principais causas de mortalidade e prolongamento de a permanência no hospital a pacientes internados (Soares et al, 2017).

Desse modo, o setor de higiene e limpeza e a função do enfermeiro no controle de infecção hospitalares aparecem com um papel primordial na prevenção e promoção a saúde do paciente, entretanto encontra uma série de problemas para a sua manutenção e/ou implementação com qualidade, como discorre Chaves et al. (2010):

O setor de higiene e limpeza, entretanto, enfrenta sérios problemas na implementação de uma filosofia de qualidade, principalmente nos fatores relacionados à equipe como número insuficiente de profissionais, falta de conhecimento de abordagem, falta de comprometimento e resistência às mudanças (Chaves et al, 2010, p. 12).

Outra vertente que deve abordada é a classificação correta de risco de infecção do ambiente hospitalar para que assim ocorra continuidade na execução da limpeza higienizantes de acordo com o tempo exigido pela categorização feita, gerando uma preservação de instrumentos utilizados nas atividades locais como também prevenção de acidentes neles (Ribeiro et al, 2017).

A avaliação contínua da conformidade à adesão a HM no serviço hospitalar é extremamente importante e deve ser realizada continuamente para garantir que as intervenções tenham o impacto desejado, além de identificar as áreas e os profissionais que requerem aperfeiçoamento (Ribeiro et al, 2017, p. 5). 
Além disso, Aragão (2017) destaca que o enfermeiro possui dificuldades de relacionar a teoria aprendida nas universidades com a pratica no trabalho cotidiano o que indispensável na assistência ao paciente, tal pratica segundo o estudo: (...) evidencia uma lacuna nos processos de formação e educação permanente, necessários para que haja uma atuação consciente e responsável no contexto do trabalho hospitalar (Aragão, 2017, p.09).

Contudo, Souza et al. (2017) discorda, os profissionais da área de saúde devem ter acesso ao aprendizado durante a sua graduação, portanto ter conhecimento desse procedimento é inerente a matriz curricular do curso de enfermagem (Souza et al, 2017, p. 3).

Entende-se assim que os materiais que são expostas nas instituições de ensino são adequadas para a construção dos enfermeiros, entretanto as elevadas incumbências do curso fazem com que os acadêmicos não consigam destrinchar o conteúdo, não o compreendendo em sua completude e, por fim, não percebendo a sua real função, que tornar-se-á ineficiente.

Logo, ressalta-se a importância da educação continuada nos serviços de saúde, em especial no setor hospitalar no que tange a higienização e a utilização correta de equipamentos de proteção individual (EPI), com o intuito de garantir a qualidade do cuidado na assistência prestada, além de promover a segurança aos pacientes. Desse modo, a busca por discernimento é essencial para a atuação do enfermeiro na saúde.

\section{Conclusão}

Em suma, percebemos a importância que o conhecimento histórico possui para a compreensão do cenário atual do país, pois, a partir das ideologias ambientais e sanitárias defendidas por ativistas do século XIX, a enfermagem torna-se protagonista na educação em saúde e prevenção de múltiplas patologias.

Em suma, é de fundamental importância que o enfermeiro adote uma visão global do campo de saúde, principalmente, nos serviços públicos, podendo assim, atuar nas tomadas de decisões de seu ambiente de trabalho, na conscientização política e crítica por parte da sua equipe e, dessa forma, reivindicar pelos os direitos desse grupo e da população para melhores condições de trabalho e atendimento clínico, respectivamente.

\section{Referências}

Aragão, J. H. A. (2017). Os pressupostos Nightingaleanos na prática hospitalar: subsídios para a enfermagem. Ver enferm UFPE on line, 11(4), 1624-1633.

Bezerra, C. M. B., Silva, B. C. O. D., Silva, R. A. R. D., Martino, M. M. F. D., Monteiro, A. I., \& Enders, B. C. (2018). Análise descritiva da teoria ambientalista de enfermagem. Enferm. foco (Brasília), 79-83.

Borson, L. A. M. G., Cardoso, M. S., Gonzaga, F. N. (2018). A teoria ambientalista de Florence Nightingale. Revista Saúde em Foco, 10(2): 25-56.

Campos, J. L; Jesus, O. A. (2016). Higiene hospitalar: a importância da limpeza na prevenção de infecções. Faculdade INESP, 2(5): 100-123.

Cazali, A. S, et al. (2020). A higiene das mãos os como prática para evitar infecções relacionadas assistência saúde no âmbito hospitalar: relato de experiência. Revista Enfermagem UFPE on-line, 9(1): 24-33.

Chaves, L. D. P. (2017). Governança e higiene e limpeza hospitalar: espaço de gestão do enfermeiro. Revista Texto \& Contexto-Enfermagem, 2017; 32(1): 2540 .

Chaves, L. D. P, et al. (2019). Governança, higiene e limpeza hospitalar: espaço de gestão do enfermeiro. Revista Texto \& Contexto-Enfermagem, 24(4): 11661174

Floriano A. A, et al. (2020). Contributo de Florence Nightingale na ascendência do cuidar em enfermagem: do contexto histórico ao cuidado contemporâneo. Revista Texto \& Contexto-Enfermagem, 9(7): 12-23.

Florentino, A. A. (2020). Análise comparativa da infecção hospitalar e intervenção no hospital unimed itapetininga no período de 2017 a 2018 . Revista Temas em saúde, 9(1): 11-15.

Grisard, N., Vieira, E. T. S. (2019). Ana Néri, madrinha da enfermagem no Brasil. Hospitais Universitários Federais, 10(2): 24-38.

Haddad, R. E, et al. (2016). Técnica de higiene das mãos e eficiência de degermantes na prevenção de infecções hospitalares. Revista Enfermagem UFPE online [internet], 1(1): 562-567.

Hospital Universitário Júlio Muller da Universidade Federal de Mato Grosso (2017). Protocolo Operacional Padrão de Limpeza Hospitalar, 2(1): 12-20. 
Research, Society and Development, v. 10, n. 3, e46610313626, 2021

(CC BY 4.0) | ISSN 2525-3409 | DOI: http://dx.doi.org/10.33448/rsd-v10i3.13626

Martins, D. L., Maia, F. S. B., Dantas, V. P. C. (2016). Procedimento Operacional Padrão (POP): higienização hospitalar. Hospitais Universitários Federais (EBSERH), 1(1): 10-20.

Merhy, E. E, et al. (2016). Políticas e sistemas de saúde no Brasil. Editora Fiocruz, 2(3): 100-102.

Moura, L. C. D, et al. (2017). Higiene e desinfecção hospitalar aliadas na segurança do paciente. Revista Temas em Saúde, 17(1): 15-20.

Moura, L. C. D, et al. (2017) Higiene e desinfecção hospitalar aliadas na segurança do paciente. Revista Temas em Saúde, 17(1): 4-17.

Padilha, M. I. C. S., Borenstein M. S. (2016). História da enfermagem: ensino, pesquisa e interdisciplinaridade. Revista Temas em Saúde, 1(1): $20-32$.

Potter, P. A., Perry, A. G. (2016) Fundamentos de enfermagem: conceitos e procedimentos. Editora Fiocruz, 5(1): 672-680.

Perry, A. G; Potter, P. A. (2019). Fundamentos de enfermagem. Editora Elsevier, 2(4): 672-680.

Prestes, M. L. M. (2016). A pesquisa e a construção do conhecimento científico: do planejamento aos textos, da escola à academia. Editora Fiocruz, 2(1): 1416.

Pereira A. S. et al. (2018). Metodologia da pesquisa científica. UFMS.

Ribeiro, J. B, et al. (2017). A higienização hospitalar: uma solução paliativa. Caderno de Graduação-Ciências Biológicas e da Saúde, 4(2): 61-70.

Rodrigues, V. P, et al. (2016). Avaliação dos hábitos de higiene bucal de crianças durante o período de internação hospitalar. Revista Texto \& ContextoEnfermagem, 10(1): 49-55.

Silveira, I. R, et al. (2019). Higiene bucal: prática relevante na prevenção de pneumonia hospitalar em pacientes em estado crítico. Revista Texto \& ContextoEnfermagem, 23(5): 697-700.

Soares, N. R. M, et al. (2017). Conhecimentos, atitudes e práticas dos profissionais de enfermagem sobre higiene das mãos no ambiente hospitalar. Revista Família, Ciclos de Vida e Saúde no Contexto Social, 5(3): 362-371.

Souza, E. C, et al. (2017). Conhecimento sobre higiene das mãos de estudantes do curso de enfermagem. Revista Científica de Enfermagem, 7(21): 41-48.

Trannin, K. P. P, et al. (2016). Adesão à higiene das mãos: intervenção e avaliação. Revista Científica de Enfermagem, 21(2): 16-20. 